\title{
Vanessa De Senarclens, Montesquieu historien de Rome. Un tournant pour la réflexion sur le statut de l'histoire au XVIII siècle
}

\section{Gianmaria Zamagni}

\section{(2) OpenEdition \\ Journals}

\section{Edizione digitale}

URL: http://journals.openedition.org/studifrancesi/36157

DOI: 10.4000/studifrancesi.36157

ISSN: 2421-5856

\section{Editore}

Rosenberg \& Sellier

\section{Edizione cartacea}

Data di pubblicazione: 1 juillet 2005

Paginazione: 164

ISSN: 0039-2944

\section{Notizia bibliografica digitale}

Gianmaria Zamagni, «Vanessa De Senarclens, Montesquieu historien de Rome. Un tournant pour la réflexion sur le statut de I'histoire au XVIII' siècle», Studi Francesi [Online], 145 (XLIX | I) | 2005, online dal 30 novembre 2015, consultato il 18 avril 2021. URL: http://journals.openedition.org/studifrancesi/ 36157 ; DOI: https://doi.org/10.4000/studifrancesi.36157

Questo documento è stato generato automaticamente il 18 avril 2021.

\section{cc) $($ ) $\ominus$}

Studi Francesi è distribuita con Licenza Creative Commons Attribuzione - Non commerciale - Non opere derivate 4.0 Internazionale. 


\title{
Vanessa De Senarclens, Montesquieu historien de Rome. Un tournant pour la réflexion sur le statut de l'histoire au XVIII siècle
}

\author{
Gianmaria Zamagni
}

\section{NOTIZIA}

VANESSA DE SENARCLENS, Montesquieu historien de Rome. Un tournant pour la réflexion sur le statut de l'histoire au XVIII siècle, Genève, Librairie Droz («Bibliothèque des Lumières», 62), 2003, pp. 292.

1 Dedicato principalmente alle montesquieuiane Considérations sur les causes de la grandeur des Romains et de leur décadence, il colto studio di Vanessa de Senarclens ha per campo d'indagine l'opera intera del Président, della quale privilegia nondimeno le raccolte di note (le Pensées, i Voyages e lo Spicilège). Le tre parti di cui è composto il volume sono relative ai tre temi principali in cui si articola il topos romano nell'opera di Montesquieu: l'effetto politico di Roma sulla Francia dopo il regno di Luigi XIV, la specificità della storia romana messa in evidenza dalla sua interpretazione, e infine le implicazioni epistemologiche di questa per una riflessione sullo statuto della storia. Tre aspetti, dunque: politico, storico e metastorico del discorso di Montesquieu su Roma, visti in una prospettiva comparativa, mettono in evidenza l'originalità e la singolarità della sua concezione della storia nel XVIII secolo.

2 Per entrare maggiormente nello studio, De Senarclens nel proprio primo capitolo elegge a esergo un passo di Simon-Nicholas-Henri Linguet, ove questi denuciava la «manie romaine» dei propri contemporanei, definendola una forma di amor proprio collettivo, mirante a trovare in Roma la genealogia della grandeur francese. Il cavaliere de Jaucourt stesso, nell'Encyclopédie, definiva Roma la «roue de la fortune», intendendo 
come «elle fournit un parcours complet de toutes les formations politiques possibles à tous les stades de leurs développement» (p. 59). Secondo Montesquieu, invece, la strumentalizzazione che la sua epoca aveva fatto della storia romana non permetteva né una buona storiografia, né una buona riflessione politica.

3 A De Senarclens interessa però piuttosto il versante storiografico della questione; il testo continua allora mettendo in evidenza il nuovo approccio, il tournant del sottotitolo appunto, rappresentato nel XVIII secolo da Montesquieu. Dopo aver indagato i fondamenti filosofici del Président, la specificità della sua storia romana è mostrata nel suo tenersi al riparo dagli usi strumentali più diffusi. Come scrive l'autrice, «Au lieu de saluer «l'exemple romain» et d'y chercher des paradigmes politiques ou moraux, l'auteur étudie son équilibre social et politique et cherche à comprendre comment celui-ci se modifie à l'usure du temps» (p. 146). La tesi della parte centrale è che la diversità, ritrovata nelle varie epoche e civiltà, «notion clef de la philosophie de Montesquieu» sfoci in una «interprétation non objectivante de l'histoire» (p. 181, usando una terminologia ermeneutica gadameriana), differente dunque da quella invalsa nel siècle philosophique.

4 È sulla scorta di quanto detto, che nella parte successiva il conflitto storiografico tra erudizione e filosofia viene conciliato da una citazione di Gibbon che prende Montesquieu a modello dello storico che «allie le sérieux de la méthode érudite avec le «génie» des philosophes» (p. 188). Per questo motivo il bordolese andrebbe a buon diritto inserito, secondo De Senarclens, nella filiazione degli storici, al contrario di quanto sostiene la linea critica secondo la quale «Montesquieu est «un philosophe» n'ayant rien à enseigner à un érudit tel Beaufort qui, lui, «raisonne en historien»» (Chantal GReLL, citata a p. 224). Tesi questa che farebbe torto al Président omettendone l'apporto alla moderna coscienza storica. La storiografia di Montesquieu sarebbe pertanto al di là del dissidio tra erudizione e filosofia, fatta anche con eleganza, non temendo egli di fare in questo modo anche della letteratura.

5 Lo studio di De Senarclens, nel reinserire Montesquieu nel novero degli storici del suo tempo, tiene vivo, con ciò stesso, il dibattito sullo statuto della storia e dell'ermeneutica, e non solo, a dire il vero, limitatamente al XVIII secolo. 